\title{
Early Symbiotic Responses Induced by Sinorhizobium meliloti ilvC Mutants in Alfalfa
}

\author{
Juan Carlos López,,$^{*}$ Daniel H. Grasso, ${ }^{1 *}$ Florian Frugier, ${ }^{2}$ Martín D. Crespi, ${ }^{2}$ and O. Mario Aguilar ${ }^{1}$ \\ ${ }^{1}$ Instituto de Bioquímica y Biologia Molecular, Universidad Nacional de La Plata, Facultad de Ciencias \\ Exactas, Calles 47 y 115, 1900-La Plata, Argentina; ${ }^{2}$ Institut des Sciences Végétales, Centre National de \\ la Recherche Scientifique, F-91198 Gif-sur-Yvette Cedex, France. \\ Accepted 22 September 2000.
}

\begin{abstract}
A mutation in the ilvC gene of Sinorhizobium meliloti 1021 determines a symbiotically defective phenotype. ilv $\mathrm{C}$ mutants obtained from different $S$. meliloti wild-type strains are able to induce root hair deformation on alfalfa roots and show variable activation of the common nodulation genes $\operatorname{nod} \mathrm{ABC}$. All of these mutants are noninfective. The presence of extra copies of nodD3-syrM in an $\mathrm{IlvC}^{-}$background does not promote nod expression but allows the detection of low levels of Nod factor production. The sulphation of the Nod factor metabolites, however, is not affected. Furthermore, IlvC ${ }^{-}$strains induce a specific pattern of starch accumulation on alfalfa roots as well as of early nodulin expression. Hence, the pleiotropic action of the $i l v C$ gene in $S$. meliloti may reveal novel complexities involved in the symbiotic interaction.
\end{abstract}

Additional keywords: isomeroreductase, plant response, symbiosis.

The symbiotic association between soil bacteria belonging to the genera Rhizobium, Sinorhizobium, Bradyrhizobium, and Azorhizobium and legumes leads to the formation of nitrogenfixing root nodules. This association is host specific, thus Sinorhizobium meliloti is able to nodulate the Medicago, Melilotus, and Trigonella species. The molecular basis of this specificity is a signal exchange between the plant and bacteria. Certain flavonoid compounds released by the plant root, together with the rhizobial regulatory protein NodD, activate the transcription of nodulation genes. These genes collectively constitute a set of rhizobial genes known as nod, nol, and noe (Dénarié et al. 1992; Schultze and Kondorosi 1998). The product of several of these genes are involved in the synthesis and excretion of signal molecules named Nod factors. The chemical structure of these molecules consists of a basic backbone of $\beta 1,4$-linked $N$-acetyl-D-glucosamine that was $N$ acylated on the nonreducing sugar and $N$-acetylated on the other residues. The chain length of this molecule depends on the strains and is determined by the NodC protein. Nod factor structures show differences in the substituents linked to the chitin oligomer backbone, which confers specificity to the

Corresponding author: O. M. Aguilar; Fax: +54 221 4226947; Telephone: +54 2214250497 ext.61; E-mail: aguilar@biol.unlp.edu.ar

*Both authors contributed equally to this work. action on the plant host (Dénarié and Debellé 1996; Spaink 1995).

The rhizobial infection begins with the attachment of bacteria to the root hair tips where deformation (Had) and curling (Hac) are induced. The bacteria entrapped within the curled root hairs (Shepherd's crooks) enter into the root by means of newly formed tubular structures known as infection threads (ITs). Concomitantly, at the site where infection takes place, dedifferentiation of the inner cortex cells occurs, giving rise to a nodule primordium. Once the ITs reach the primordium, bacteria are transferred as symbiosomes into the cytoplasm of the inner cortical cells and differentiate into the nitrogen fixing form known as bacteroids (Hirsch 1992). Alfalfa roots form indeterminate nodules that have a persistent apical meristem, followed by an infection zone containing a network of branched ITs, a nitrogen-fixing zone where the cells are filled of bacteroids, and a senescence zone where bacterial cells degenerate (Vasse et al. 1990). In addition to Nod factors, other bacterial components, including exopolysaccharides (EPS), lipopolysaccharides (LPS), capsular polysaccharides (CPS), and cyclic $\beta$-(1,2)-glucans are involved in the symbiotic process (Breedveld and Miller 1994; Kannenberg and Brewin 1994).

Beside the nodulation genes, rhizobial genes involved in amino acid metabolic pathways also are required for an effective nodulation of the plant hosts (Beringer et al. 1980; Kerppolla and Kahn 1988; Ninner and Hirsch 1998; Pain 1979; Taté et al. 1999). We reported that a mutant auxotroph to isoleucine and valine mutated in the $i l v \mathrm{C}$ gene of $S$. meliloti 1021 is symbiotically defective (Aguilar and Grasso 1991). This gene encodes the enzyme acetohydroxiacid isomeroreductase, which catalyses the second step in the biosynthetic pathway for isoleucine and valine. Although this mutant is able to induce root hair deformation on alfalfa roots (Hirsch et al. 1982), we found that nodulation genes nodABC are not activated by the inducer luteoline (Aguilar and Grasso 1991). This suggests that a low basal level of nod gene expression may allow the synthesis of sufficient amounts of Nod factors for the plant response. Alternatively, in planta nod induction might be different from that measured in the mentioned assay in vitro.

Here we examined the symbiotic behavior of $S$. meliloti $i l v \mathrm{C}$ mutants obtained from different wild-type strains to gain insight into the putative role of this gene in nodulation. The $i l v \mathrm{C}$ mutation negatively affects activation of $\operatorname{nod} \mathrm{ABC}$ genes, 
but the extent of this effect depends upon the strain studied. Overall, $\mathrm{IlvC}^{-}$strains from different genetic backgrounds were noninfective, although they induced a specific pattern of starch accumulation on alfalfa roots. Thin-layer chromatography (TLC) analysis showed that the major sulphated forms of Nod factor could be detected in culture supernatants of $\mathrm{IlvC}^{-}$ strains. Analysis of early nodulin gene expression in $i l v \mathrm{C}$ structures revealed a specific pattern that was different from those induced by wild-type, Nod, or EPS mutant $S$. meliloti strains. Our results demonstrate that the $i l v \mathrm{C}$ function is pleiotropically required for symbiosis.

\section{RESULTS}

\section{Isolation of $S$. meliloti ilvC mutants.}

In order to assess the phenotype of ilvC mutants in different genetic backgrounds, we carried out site-specific mutagenesis of wild-type strains S. meliloti 41 and L5-30 These extensively studied strains have phenotypic and genotypic differences compared with S. meliloti 1021. Briefly, S. meliloti 41 contains a functional NolR repressor and constitutively produces exopolysaccarides (EPS) EPS I, EPS II, and CPS, whereas strain S. meliloti L5-30 harbors moc and mos genes and nodulates other hosts in addition to Medicago spp. (Kondorosi et al. 1989; Rossbach et al. 1995; Wexler et al. 1996; Williams et al. 1990).

Mutants were obtained by fragment-specific recombination with the $i l v \mathrm{C}:: \operatorname{Tn} 5 \mathrm{DNA}$ sequence cloned from the $i l v \mathrm{C} \mathrm{mu-}$ tant Sm1028 in the suicide plasmid pQB2. Transconjugants unable to grow on minimal medium were analyzed by Southern blot with a Tn5 probe. All tested transconjugants showed a single restriction endonuclease designation (EcoRI) fragment identical in size to that found by probing EcoRI-digested DNA from the Sm1021 ilvC mutant strain Sm1028 (data not shown). From these transconjugants, one mutant was selected from wild-type strains SmL5-30 and Sm41, which were named SmM6 and SmM41, respectively, and used for further analysis. The only requirement of isoleucine and valine for growth was confirmed (data not shown). Herein, unless specifically stated, IlvC strains refer to mutants Sm1028, M6, and M41.

The $\mathrm{IlvC}^{-}$strains were tested for their capacity to nodulate alfalfa. All of them were unable to induce nodules, although approximately $10 \%$ of the inoculated plants with the $\mathrm{IlvC}^{-}$ strains presented small, white ineffective nodules, as previously found with the Sm1028 strain (Aguilar and Grasso 1991). Bacterial growth was observed next to the root, allowing us to assume that amino acids present in root exudates are sufficient for mutant growth. Plasmid pQB11 containing the wild-type ilvC gene of $S$. meliloti was transferred into SmM41 and SmM6 and restored the prototrophy and the ability to induce a successful symbiotic association with alfalfa.

These results confirmed our earlier observation performed on a derivative of strain Sm1021 and demonstrate the importance of $i l v \mathrm{C}$ for symbiosis as a rather general phenomena in the $S$. meliloti spp.

\section{nod promoter activity varies among different ilvC mutants.}

In order to assess whether the ilvC mutation in strains M41 and M6 affects transcription of common nodulation genes, as reported for the mutant 1028 (Aguilar and Grasso 1991), we used the plasmid pRmM57 carrying a gene fusion between the nod $\mathrm{ABC}$ promoter of $S$. meliloti and the lac $\mathrm{Z}$ reporter gene (Mulligan et al. 1985). Introduction of this plasmid in the wild-type and $\mathrm{IlvC}^{-}$strains allowed us to test the flavonoidinducing capacity of nodulation genes in each background. Levels of $\beta$-galactosidase differed among the wild-type strains assayed (Table 1), and the activity in strains Sm1021 and L530 was five times higher than in Sm41, which is in agreement with the active presence of the repressor gene nolR in strain Sm41 (Kondorosi et al. 1989). Either in rich-medium tryptone (TY) or minimal-medium GTS (Kiss et al. 1979), nodABC gene expression was found to be lower in each of the three $i l v \mathrm{C}$ mutant strains compared with the respective wild type. The individual measurements, however, differed among the mutant strains. For instance, a drastic decrease in nod gene expression to approximately $5 \%$ of the activity in the wildtype strains was found in mutants M41 and 1028, respectively, whereas the decrease of activity in SmM6 was lower, down to approximately $25 \%$ of the wild-type strain L5-30.

It has been shown that multiple copies of nodD3-syrM genes deregulate the expression of common nod genes (Györgipal et al. 1988). In order to assess the effect of the high number of copies of the regulatory genes nodD3-syrM on the expression of nod genes in the ilv $\mathrm{C}$ mutant strains, plasmid pNID6 was introduced in ilvC strains. The $\beta$ galactosidase activity determined in strains carrying the nodABC-lacZ gene fusion is shown in Table 1. Transcription activity of nod genes in JM57(pNID6) was 30 times higher than in strain JM57, indicating that the nodD3-syrM genes have a positive effect on the nod promoter as expected (Kondorosi et al. 1991). In contrast, the plasmid pNID6 had no effect on the nod promoter activity in the $i l v \mathrm{C}$ background of strain JC1 (Table 1). These results suggest that the ilvC mutation prevents activation of the nod promoter by the regulatory genes nod D3-syrM. In addition, our data demonstrate that the effect of the ilv $\mathrm{C}$ mutation on the nod gene expression varies among different strains. Noteworthy is that the level of the remaining nod promoter activity in mutant SmM6 was higher than that of wild-type strain Sm41, yet SmM6 was unable to form wild-type nodules.

\section{ilv C mutation reduces Nod factor production without affecting sulphation.}

The production of Nod factors by the $\mathrm{IlvC}^{-}$strains was investigated by in vivo radioactive labeling of Nod metabolites and TLC analysis. As previously described, very low, undetectable amounts of Nod factors are produced by strain 1021 (Baev et al. 1992). In order to increase Nod-factor yields, plasmid pNID6 containing the regulatory genes syrM and nodD3 (Györgipal et al. 1988) was transferred into S. meliloti strains. Culture supernatants of the resulting strains were analyzed with TLC. Several spots were detected in samples from wild-type strains SmL5-30(pNID6) and Sm1021(pNID6) (Fig. 1, lanes 1 and 6), whereas no discrete spots were found in a $\mathrm{Nod}^{-}$mutant strain (Fig. 1, lane 5), which is unable to synthesize the basic lipooligosaccharide structure of the Nod factor (Dénarié et al. 1992). IlvC $^{-}$ (pNID6) strains produced significantly lower amounts of Nod factors than the wild-type strains, most likely as a result of reduced nod-promoter activity. Nevertheless, several spots 
that correspond to spots absent in supernatants of a $\mathrm{NodH}^{-}$ mutant strain (Fig. 1, lane 4) were revealed with TLC (Fig. 1, lanes 3 and 7). Hence, these spots could be assigned to the major sulphated forms of Nod factors. Complementation of the Sm1028 strain with the $S$. meliloti wild-type ilvC gene restored Nod factor production to wild-type levels (Fig. 1, lane 2). Although pNID6 has no effect on nodABC-promoter activity in the $\mathrm{IlvC}^{-}$mutant strain $\mathrm{JC} 1$ (Table 1), we observed that pNID6 has a positive effect on Nod factor production in the $\mathrm{IlvC}^{-}$mutant strains Sm1028 and SmM6 (data not shown).

The main effect of an ilv $\mathrm{C}$ mutation, therefore, is its quantitative decrease in Nod factor production without affecting its sulphation. This effect was observed in all mutants tested, regardless of the level of nod promoter activity. For instance, strains SmM6 and Sm1028 produced similar levels of the Nod factor, yet differed in their nod transcriptional activity (Table 1). The basis of this discrepancy is unknown to us.

Table 1. nod promoter activity in $\mathrm{IlvC}^{-}$strains

\begin{tabular}{lcc}
\hline & \multicolumn{2}{c}{$\beta$-galactosidase (Miller units) } \\
\cline { 2 - 3 } Strain & \multicolumn{1}{c}{$\mathbf{L}$} & $\mathbf{+ L}$ \\
\hline Sm1021(pRm57) & 3.2 & 150.9 \\
Sm1028 (pRm57) & 5.5 & 10.1 \\
Sm41 (pRm57) & 22.7 & 113.8 \\
SmM41 (pRm57) & 18.3 & 22.2 \\
SmL530 (pRm57) & 9.6 & 206.8 \\
SmM6 (pRm57) & 12.5 & 57.5 \\
SmJM57 & 26.6 & nd \\
SmJM57 (pNID6) & 711.3 & nd \\
SmJC1 & 26.2 & nd \\
SmJC1 (pNID6) & 31.1 & nd \\
\hline
\end{tabular}

${ }^{a}$ Rhizobial cells were grown in GTS medium with Ile and Val, except strains Sm41 (pRm57) and SmM41 (pRm57), which were grown in rich medium tryptone as a result of the low activity found in medium GTS. nd = nondetermined; $+\mathrm{L}=$ supplementation with $10 \mu \mathrm{M}$ luteolin; $-\mathrm{L}=$ absence of luteolin.

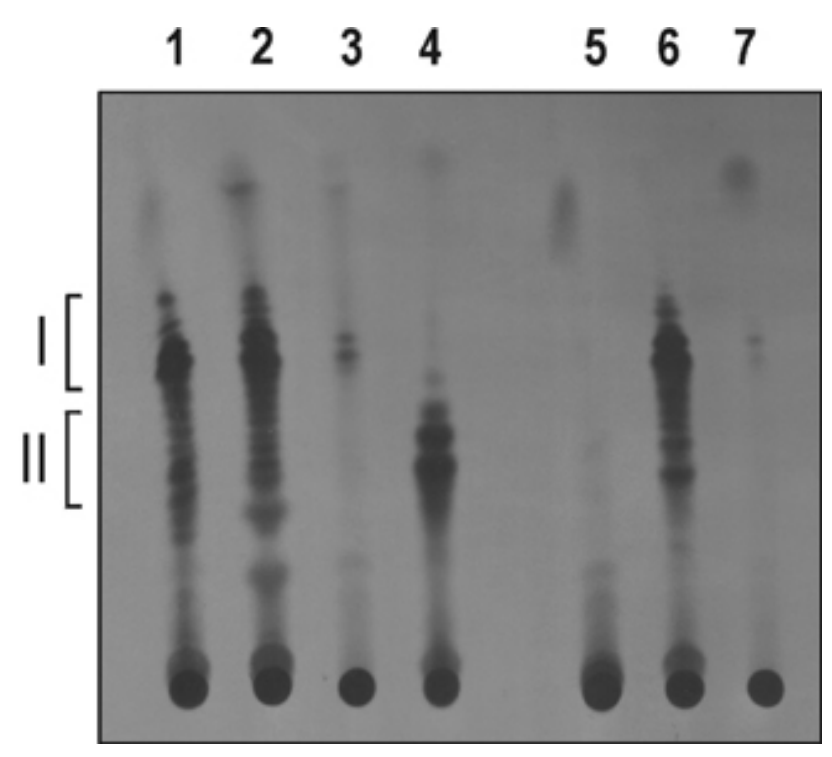

Fig. 1. Butanol extracts of ${ }^{14} \mathrm{C}$-labeled Nod metabolites produced by the following strains containing the pNID6 plasmid. Lane 1, Sm1021; lane 2, Sm1028(pQB11); lane 3, Sm1028; lane 4, Sm1021 nodH::Tn5; lane 5, Sm1021 nodC::Tn5; lane 6, SmL5-30; lane 7, SmM6. I and II indicate sulphated and nonsulphated Nod metabolites, respectively.

\section{IlvC ${ }^{-}$strains do not form ITs.}

The induction of plant response to inoculation with $\mathrm{IlvC}^{-}$ strains was investigated by microscopic examination. In order to facilitate these cytological studies with fluorescence microscopy, plasmid pTB93F (Gage et al. 1996) expressing the sequence coding for the green fluorescent protein was introduced into the different strains. Seven days after inoculation, wild-type strains induced root hair curling and ITs (Fig. 2A). Nodules induced by these strains showed green fluorescence in the central region as expected (Gage et al. 1996; data not shown). Alfalfa plants inoculated with $\mathrm{IlvC}^{-}$strains showed abundant hypertrophied root hairs with numerous branchings and swellings and, only exceptionally, curled root hairs (Fig. $2 \mathrm{~B}$ and data not shown). Green-fluorescent bacteria were attached to these root hairs, but we were unable to detect ITs. Nodules were undetectable even after 5 weeks of inoculation, although thick roots surrounded by long and deformed root hairs were observed in approximately $70 \%$ of the plants. However, small nodule-like structures without fluorescent bacteria inside (data not shown) were observed in approximately $10 \%$ of the plants. The plant response induced by the different $\mathrm{IlvC}^{-}$strains was the same. Our results indicate that $i l v \mathrm{C}$ mutant strains are still able to induce some plant response; however, the interaction between alfalfa and $i l v \mathrm{C}$ mutants is blocked at a very early step.

\section{Specific molecular and cytological patterns of plant responses are induced by $\mathrm{IlvC}^{-}$strains.}

In order to assess plant response to inoculation with $i l v \mathrm{C}$ mutant strains at cellular and molecular levels, cortical cell activation (CCA) and accumulation of early nodulin gene transcripts in the inoculated tissues were investigated. To monitor CCA, a bioassay based on starch accumulation in inoculated roots was used (Ardourel et al. 1994). Seven days after inoculation with wild-type and ilv $\mathrm{C}$ mutants, respectively, starch accumulation in cortical cells was found. In the case of the wild type, starch accumulated in front of the ITs (Fig. 3A). Amyloplast accumulation also was found in the infection zone III of mature wild-type-induced nodules (data not shown). The pattern of starch accumulation induced by the different $\mathrm{IlvC}^{-}$strains were similar among them but differed from those found within the wild-type strains. Starch accumulation also was detected in cortical cells from some secondary roots (data not shown). This became more evident 14 days after inoculation (Fig. 3B) when cellular clusters with intense amyloplast accumulation that consisted of small cortical cells separated by periclinal septa were observed (Fig. 3C).

Four weeks after inoculation, the peripheral cells of secondary roots with starch accumulation were distended and hypertrophied (Fig. 3D). The morphology of this region of the root was similar to that previously described as "galls" (Hirsch et al. 1982). The thickness of the secondary roots was more evident in zones where intense amyloplast accumulation was observed. Small, white root structures appeared at low frequency. Interestingly, at this stage numerous tertiary roots containing cells filled with starch granules were observed (Fig. 3D). In order to investigate whether these plant responses to ilvC inoculation depend upon Nod factor activity, a double-mutant ilvC-nodC strain SmM131 was obtained from an Sm1021-derivative NodC $^{-}$(Table 2) and used to inoculate 
alfalfa. Examination of inoculated roots revealed absence of amyloplast accumulation. This result demonstrates that activation of cortical cells in response to the IlvC mutant strains requires wild-type nodulation genes from the bacterial symbiont. This also suggests that, in spite of the low level of production, Nod factors are still required. In addition, these results demonstrated that ilvC mutants induce responses in cortical cells different from those found with wild-type strains.

Induction of early nodulin genes was investigated by reverse transcription-polymerase chain reaction (RT-PCR) analysis of the root structures induced by the $\mathrm{IlvC}^{-} \mathrm{Sm} 1028$ strain. This pattern of expression was analyzed for multiple molecular markers (Jiménez-Zurdo et al. 2000) and compared with the patterns observed for $\mathrm{NodC}^{-}$-inoculated roots, spontaneous nodules derived from $\mathrm{Nar}^{+}$plants (Truchet et al. 1989), and nodules induced by the Exo ${ }^{-}$strain 0540, respectively. Several molecular markers expressed in the different nodule types were assayed, and a specific pattern of expression was found for an ilvC mutant (Fig. 4). Enod40 was strongly expressed, whereas other nodulins such as MsNod800, Mscp10, and MsNod20 were not detected. This analysis reveals a specific molecular response to ilvC mutants, which may indicate that signals other than Nod factors also are able to induce plant responses. Alternatively, induction of certain nodulin genes can be achieved with the very low level of Nod factors produced by the $\mathrm{IlvC}^{-}$strains.

\section{DISCUSSION}

The defective symbiotic phenotype of ilv $\mathrm{C}$ mutants is not related to nutritional limitations because other $S$. meliloti $\mathrm{Ilv}^{-}$ auxotrophic mutants display a wild-type nodulation phenotype
(Aguilar and Grasso 1991) and ilvC mutants increase their bacterial mass in the zone next to the roots (our unpublished data). This indicates that isoleucine and valine are not limiting bacterial growth in the alfalfa rhizosphere. The obvious inference is that the $i l v \mathrm{C}$ mutation specifically affects symbiosis through a different mechanism. Here we present studies aimed to gain insight into the role of $i l v \mathrm{C}$ in symbiosis by identifying its possible targets in the early steps of nodulation.

Several rhizobial genes have been identified that are involved in different stages of nodule development. For instance, genes nod, nol, and noe are required during the very early events of infection such as IT formation (Dénarié et al. 1992, Schultze and Kondorosi 1998). Genes involved in EPS production are needed for bacterial invasion, whereas genes bac, nif, and fix participate in late stages of rhizobia differentiation or in the nitrogen-fixation process (Hirsch 1992; Leigh et al. 1985). The symbiotic interaction between ilv $\mathrm{C}$ mutants and alfalfa is blocked at a very early step. $\mathrm{IlvC}^{-}$strains were able to induce root hair curling, CCA, and induction of a few nodulin genes. From these results, we can conclude that $i l v \mathrm{C}$ mutants retain some capability to induce plant responses and that this pattern is different from previously described defective nodulation phenotypes.

It is clear that ilv $\mathrm{C}$ mutation blocks the induction of the nod $\mathrm{ABC}$ promoter. Since we had previously demonstrated that the regulatory gene nod $\mathrm{D} 1$ is expressed in the $i l v \mathrm{C}$ mutant (Aguilar and Grasso 1991), we assume that the regulatory genes nodD3 and syrM carried in pNID6 also are expressed in such genetic background. The impact of the ilv $\mathrm{C}$ mutation on the nod expression varies among the different strains, suggesting that intrinsic mechanisms could determine the degree of inactivation. For instance, the ilv $\mathrm{C}$ mutant that is derivative of wild-type strain SmL5-30 and harbors moc and mos genes

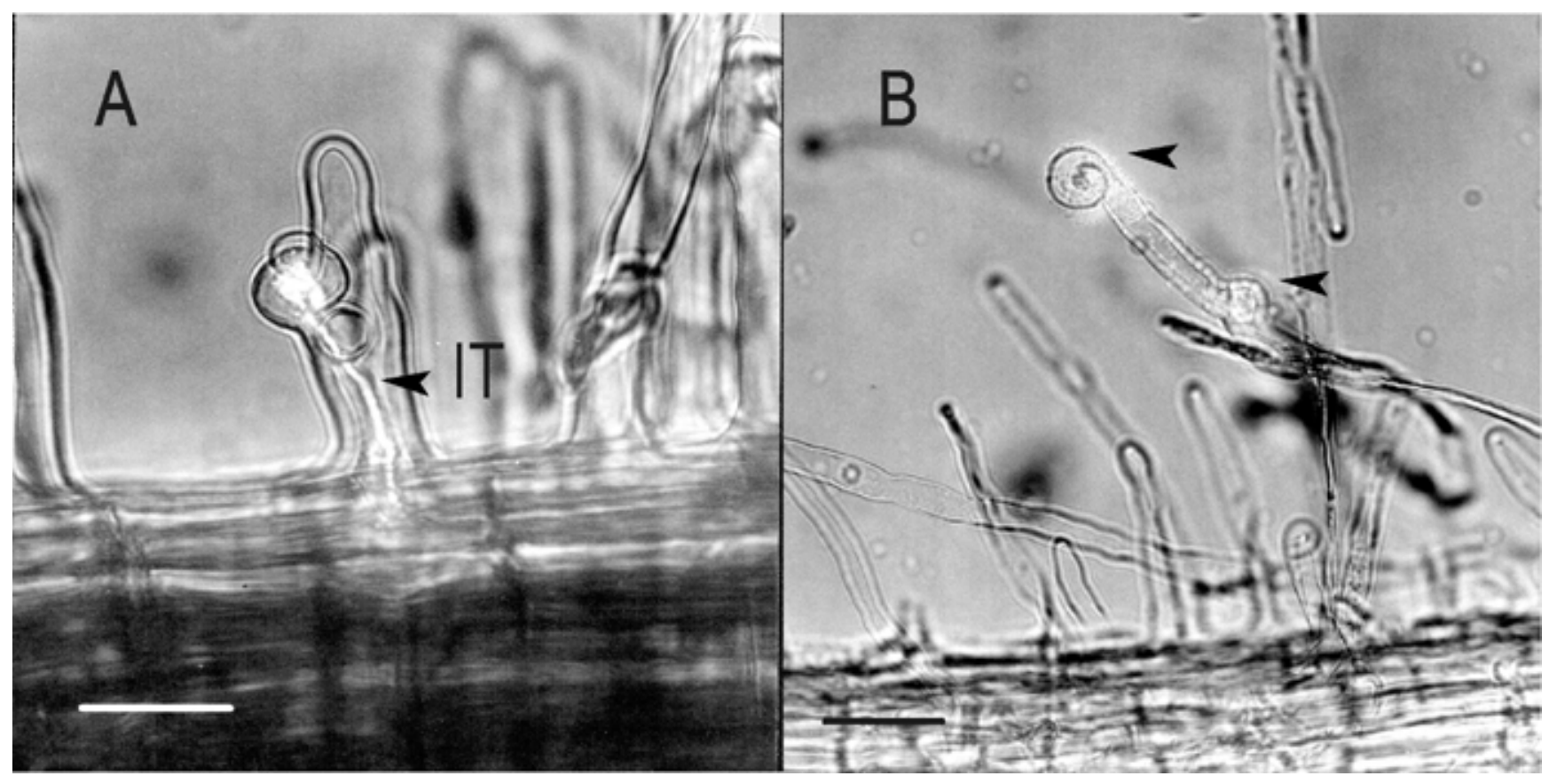

Fig. 2. Medicago sativa plants were inoculated with strains carrying the plasmid pTB93F. Infection process was followed by fluorescence microscopy. A, Curling and infection threads (ITs) observed 7 days after inoculation with wild-type strain SmL5-30. B, Occasional curling, but no ITs were observed with mutant SmM6. Arrowheads = attachment of the fluorescent bacteria to the root hairs. 
expressed a much higher residual nod activity than mutants from the other two wild-type strains. Whether the moc and genes or other particular function of L5-30 is important in modulating the effect of ilv $\mathrm{C}$ mutations needs to be investigated. On the basis of a consistent negative effect of $i l v \mathrm{C} \mathrm{mu-}$ tations on nod gene expression, it is possible to speculate that the nonspecific binding of a molecule generated in an $i l v \mathrm{C}$ background may impair the molecular interaction between the nod promoter and the NodD activator. In this case, the ilvC mutants should induce normal nodules if coinoculated with another strain able to provide Nod factors, as demonstrated for Nod $^{-}$mutants (Kapp et al. 1990). Our results of coinoculation experiments in which the $\mathrm{IlvC}^{-}$mutants and $\mathrm{Exo}^{-}$mutants were combined, however, resulted in defective nodules identical to those found with the $\mathrm{Exo}^{-}$mutant (data not shown). These results indicated that the ilvC mutation may affect another molecule essential for effective nodulation, in addition to the Nod factor. Because nodules were observed when $\mathrm{IlvC}^{-}$

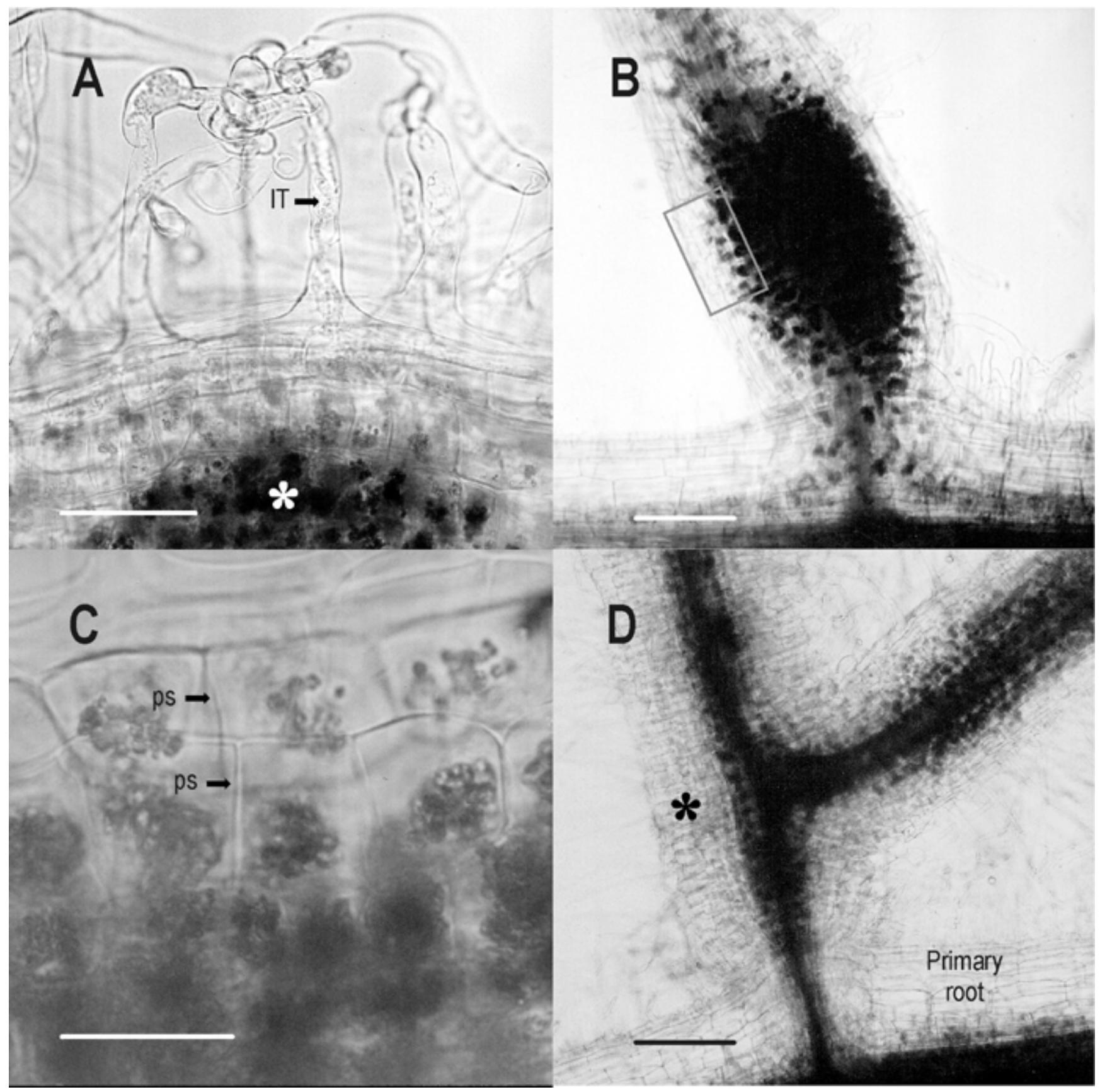

Fig. 3. A to C, Pattern of starch accumulation in cortical cells of Medicago sativa inoculated with wild-type strains and $\mathrm{IlvC}^{-}$derivatives. A, $*=$ cortical cell activation that takes place in front of infection threads in roots inoculated with strain SmL5-30. B, Thickness of secondary roots with heavy starch accumulation that takes place 14 days after inoculation with SmM6. Rectangle = zone shown in $\mathbf{C}$, where the cortical cells appear reduced in volume and separated by periclinal septa (ps). D, 4 weeks after inoculation with $i l v$ C mutant SmM6. $*=$ peripheral cells of secondary roots found distended and hypertrophied. Tertiary root containing cells filled with starch granules was observed. Bars: $\mathbf{A}=50 \mu \mathrm{m} ; \mathbf{B}$ and $\mathbf{D}=200 \mu \mathrm{m} ; \mathbf{C}=25 \mu \mathrm{m}$. 
mutant strains were coinoculated with wild-type strains in alfalfa, we ruled out the possibility that $i l v \mathrm{C}$ mutants produce compounds inhibitory of nodulation (data not shown). Our conclusion is that $i l v \mathrm{C}$ mutations pleiotropically affect $S$. meliloti

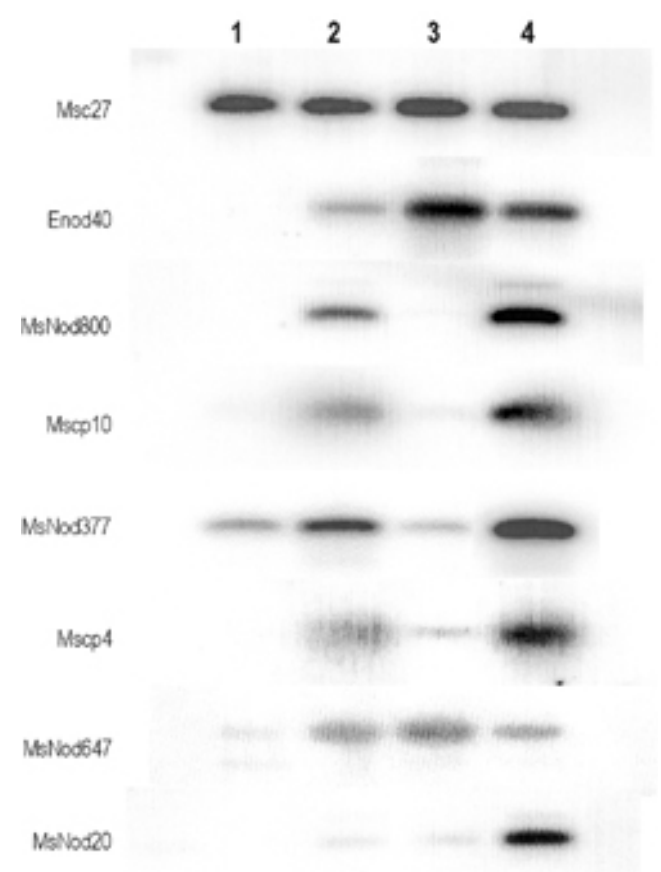

Fig. 4. Reverse transcription-polymerase chain reaction (RT-PCR) analysis of nodulin expression. Total RNA from the following tissues were used as a template for cDNA synthesis. Lane 1, roots inoculated with the nodC mutant; lane 2, spontaneous nodules; lane 3, structures induced by Sm1028; lane 4, nodules induced by the exo mutant. cDNAs were PCR amplified with specific primers for the nodulin genes (left) and analyzed by Southern blot. nodulation genes and other functions required for symbiosis.

$\mathrm{IlvC}^{-}$mutant strains do not induce IT formation, but roothair curling and specific starch accumulation, mainly in secondary roots, was observed. The amyloplast accumulation pattern is different to those reported for the double-mutant nod $\mathrm{F}-\mathrm{L}$ strain Sm GMI6628 ( $\mathrm{Hac}^{+} \mathrm{Inf}^{-}$) (Ardourel et al. 1994) or the exoY mutant Sm 0540 (data not shown). This suggests that $i l v \mathrm{C}$ affects a rhizobial component other than the Nod factor, although Nod-factor activity is required for this response. The ability to carry sulphation on Nod factors seems to be more of a determinant of nodulation than its secreted amounts because mutant strains such as $\operatorname{nod} \mathrm{M}$, which show low levels of sulphated Nod factors, are still able to form nitrogen-fixing nodules (Baev et al. 1992). In contrast, nod $\mathrm{H}$ mutants were unable to induce nodules (Roche et al. 1991). Nod-factor production by ilvC mutants is similar to that reported for $n o d \mathrm{M}$ mutants, indicating that the $i l v \mathrm{C}$-induced starch-accumulation pattern is not likely a simple consequence of reduced Nod-factor secretion.

The possibility that $\mathrm{IlvC}^{-}$strains are affected in EPS production is rather low because calcofluor assays evidenced fluorescence similar to that of the wild-type strains. In addition, in the case of mutant strain SmM41, a Sm41 derivative that produces EPS I, EPS II, and CPS, KPS can replace EPSs during symbiotic nodule development (Williams et al. 1990).

Nevertheless, how the $i l v \mathrm{C}$ gene product plays a role in symbiosis remains an interesting yet still intriguing issue. The findings that the $i l v \mathrm{C}$ gene of yeast may play a novel function in the stability of mitochondrial DNA and that the enzyme encoded by the $i l v \mathrm{C}$ gene can function as an RNA-binding protein add new roles for this gene that differ from the wellcharacterized involvement in the metabolic pathways (Hentze 1994; Zelenaya-Troitskaya et al. 1995). This also presents new perspectives when considering the ilvC pleiotropic effects in a symbiotic interaction.

Table 2. Bacterial strains and plasmids

\begin{tabular}{|c|c|c|}
\hline Strains or plasmids & Characteristics & Source or reference \\
\hline \multicolumn{3}{|l|}{ Sinorhizobium meliloti } \\
\hline 1021 & Wild type, $\mathrm{Sm}^{\mathrm{r}}$ derivative of $\mathrm{Sm} \mathrm{SU} 47$ & Meade et al. 1982 \\
\hline L5-30 & Wild type, $\mathrm{Sm}^{\mathrm{r}}$ & Kowalski et al. 1970 \\
\hline 41 & Wild type & A. Kondorosi \\
\hline 1028 & $i l v \mathrm{C}:: \operatorname{Tn} 5$ mutant of Sm1021 & Aguilar and Grasso 1991 \\
\hline M6 & $i l v \mathrm{C}:: \operatorname{Tn} 5$ mutant of SmL5-30 & This work \\
\hline M41 & $i l v \mathrm{C}:: \operatorname{Tn} 5$ mutant of $\mathrm{Sm} 41$ & This work \\
\hline $\operatorname{nodC}$ & $\operatorname{nod} \mathrm{C}:: \operatorname{Tn} 5$ mutant of $\mathrm{Sm} 1021$ & A. Kondorosi \\
\hline $\operatorname{nod} \mathrm{H}$ & $\operatorname{nod} \mathrm{H}:: \operatorname{Tn} 5$ mutant of Sm1021 & A. Kondorosi \\
\hline 0540 & exoY::Tn5 mutant of Sm1021 & Müller et al. 1988 \\
\hline Sm JC1 & $i l v \mathrm{C}:: \operatorname{Tn} 5$ mutant of JM57 & This work \\
\hline JM57 & Sm1021 nolRpSym nodC::lacZ & Mulligan and Long 1985 \\
\hline SmM131 & $\begin{array}{l}\text { ilvC mutant derivative of nod } \mathrm{C} \text { strain (obtained by homologous recombination of the suicide } \\
\text { plasmid pMA58) }\end{array}$ & This work \\
\hline \multicolumn{3}{|c|}{${ }^{P}$} \\
\hline \multirow{2}{*}{\multicolumn{3}{|c|}{ К }} \\
\hline & & \\
\hline pQB2 & $\begin{array}{l}\text { pSUP } 205 \text { carrying } 11-\mathrm{kb} \text { EcoRI restriction fragment of Sm } 1028 \text { containing a Tn } 5 \text { inserted in } \\
\text { the } i l v \mathrm{C} \text { gene }\end{array}$ & Aguilar and Grasso 1991 \\
\hline pQB11 & $i l v \mathrm{C}$ from 1021 in $\mathrm{pSUP} 104, \mathrm{Cm}^{\mathrm{R}}, \mathrm{Tc}^{\mathrm{R}}$ & Aguilar and Grasso 1991 \\
\hline pRmM57 & $\operatorname{nod} \mathrm{ABC}-l a c \mathrm{Z}, \mathrm{Sp}^{\mathrm{R}}, \mathrm{Tc}^{\mathrm{R}}$ & Mulligan and Long 1985 \\
\hline pTB93F & ptrp-GFP-S65T in pMB393. $\mathrm{Sp}^{\mathrm{R}}, \mathrm{Cm}^{\mathrm{r}}$ & Gage et al. 1996 \\
\hline pNID 6 & Containing nod $\mathrm{D} 3-s y r \mathrm{M} \mathrm{Tc} \mathrm{R}^{\mathrm{R}}$ & Györgipal et al. 1988 \\
\hline pRK2013 & Helper plasmid for mobilization of IncP and IncQ plasmids, $\mathrm{Km}^{\mathrm{r}}$ & Ditta et al.1980 \\
\hline pMA58 & $\begin{array}{l}\text { pSUP102 carrying the HindIII-BamHI fragment from plasmid pQB11 with a lacZ-Gm cas- } \\
\text { sette (Becker et al. 1995) inserted in the SmaI site of the } i l v \text { C gene }\end{array}$ & Aguilar (unpublished) \\
\hline
\end{tabular}




\section{MATERIALS AND METHODS}

Bacterial strains, plasmids, and media.

Strains and plasmids used in this study are listed in Table 2. Escherichia coli strains were maintained on Luria-Bertani agar. S. meliloti strains were grown on TY medium or GTS minimal medium. When necessary, amino acids isoleucine and valine were added at $0.40 \mathrm{mM}$ final concentration. Antibiotic concentrations for $E$. coli and $S$. meliloti were (micrograms per milliliter): tetracycline (Tc) 10 and 10, chloramphenicol $(\mathrm{Cm}) 60$ and 100, kanamycin/neomycin $(\mathrm{Km} / \mathrm{Nm}) 25$ and 100, spectinomycin (Sp) 200 and 200, and streptomycin (Sm) 400 for S. meliloti.

Bacterial biparental matings were carried out as described (Simon 1984) with E. coli S17-1 as a donor strain. The transfer of pNID6 and pTB93F plasmids from E. coli to $S$. meliloti was carried out by triparental mating with helper plasmid pRK2013 (Ditta et al. 1980).

\section{Southern analysis.}

Total DNA from the strains under study were digested with EcoRI and analyzed by Southern blotting with ${ }^{32} \mathrm{P}$ radiolabeled pQB2 (Table 2) as a probe, as previously described (Aguilar and Grasso 1991).

\section{Analysis of nod promoter activity.}

Assays for $\beta$-galactosidase activity were performed as described (Miller 1972). Rhizobial strains carrying the pRmM57 plasmid (Table 2) were grown with continuous shaking at $28^{\circ} \mathrm{C}$ in TY or GTS (plus isoleucine and valine) medium supplemented with Tc. To assay for expression induction of common nod genes, diluted cultures in fresh medium (optical density [OD] at $600 \mathrm{~nm}$ of 0.05 ) were incubated for $16 \mathrm{~h}$ with and without $10 \mu \mathrm{M}$ luteolin. Units of $\beta$-galactosidase were calculated as indicated by Miller (1972). Reported data are the averages of three independent experiments, each performed twice.

\section{TLC analysis of Nod factor production.}

In vivo labeling of nod factor was carried out as described (Baev et al. 1992). One-milliliter cultures grown at $\mathrm{OD}_{600}$ of 0.4 in GTS supplemented with isoleucine and valine were centrifugated. The supernatant was extracted with $0.5 \mathrm{ml}$ of water-saturated 1-butanol. The residue after lyophilization was taken up in $20 \mu \mathrm{l}$ of butanol with $2 \mu \mathrm{l}$ of butanol applied on TLC plates (HPTLC, RP-18) (Merck, Rahway, NJ, U.S.A.) and run with $45 \%$ acetonitrile-water. The plate was exposed to X-Omat film (Eastman Kodak Co., Rochester, NY, U.S.A.) for 10 days and developed following the manufacturer's instructions.

\section{Plant assays.}

Alfalfa ( $M$. sativa cv. cuf101) seeds were surface sterilized by shaking $2 \mathrm{~min}$ in ethanol and $15 \mathrm{~min}$ in $0.2 \% / \mathrm{vol} \mathrm{HgCl}_{2}$ in $\mathrm{HCl}(0.5 \% \mathrm{vol} / \mathrm{vol})$ solution. The seeds were extensively washed with sterile water, allowed to germinate $24 \mathrm{~h}$ in the dark, and transferred to sterile petri dishes with Jensen medium slants (Jensen 1942). Four plants per plate were used. After overnight growth, each plant root was inoculated with $50 \mu \mathrm{l}$ of bacterial suspension of approximately $10^{8}$ rhizobia per milliliter in sterile water. For coinoculation experiments,
$50 \mu \mathrm{l}$ of a mixture 1:1 of those suspensions were placed onto the roots. The plants were incubated vertically in a growth chamber at $22^{\circ} \mathrm{C}$ with a 16 -h photoperiod. At least 20 alfalfa seedlings were tested for each experimental condition. In addition, growth gamma-irradiated plastic pouches with $10 \mathrm{ml}$ of Jensen medium were used to confirm the results obtained on plates.

\section{Microscopic methods.}

Fluorescence microscopy was used to study the early events of symbiosis with plants inoculated with bacterial strains carrying plasmid pTB93F (Gage et al. 1996) The entire roots were mounted in water on a microscopic slide and examined.

Histochemical staining of starch was done, as previously described, but without glutaraldehyde fixation (Ardourel et al. 1994). All light microscopy observations were performed on at least 10 plants for each experimental condition. Specimens were examined by a JENA microscope (Carl Zeiss Inc., Thornwood, NY, U.S.A.) with a filter set for fluorescence microscopy (470 to 490 excitation and 520- to 560-nm barrier filter).

\section{Expression analysis of nodulin genes.}

RT-PCR experiments were done with total RNAs from different nodule types and nodC-inoculated roots for cDNA preparation. Amplification was done on $6 \mathrm{ng}$ of cDNAs for various multiple markers with an adequate number of cycles in parallel with oligonucleotides specific to the $M s c 27$ clone, as described (Jimenez-Zurdo et al. 2000). The names and accession numbers of the different molecular markers have been reported by Jimenez-Zurdo et al. (2000) (Mscp4 is Msca1; carbonic anhydrase). Msca1 accession number: X93312; Msenod40 accession number: X80263.

\section{ACKNOWLEDGMENTS}

We thank A. Kondorosi for constructive discussions and J. JimenezZurdo for help in RNA extraction. O. M. Aguilar is a member of the Research Career CONICET (Argentina). J. C. López was supported by a UNLP fellowship. This work was partly supported by the Ecos-Sud Programme between France and Argentina.

\section{LITERATURE CITED}

Aguilar, O. M., and Grasso, D. H. 1991. The product of the Rhizobium meliloti ilv $\mathrm{C}$ gene is required for isoleucine and valine synthesis and nodulation of alfalfa. J. Bacteriol. 173:7756-7764.

Ardourel, M., Demont, N., Debellé, F., Maillet, F., de Billy, F., Promé, J.-C., Dénarié, J., and Truchet, G. 1994. Rhizobium meliloti lipooligosaccharide nodulation factors: Different structural requirements for bacterial entry into target root hair cells and induction of plant symbiotic developmental responses. Plant Cell 6:1357-1374.

Baev, N., Schultze, M., Barlier, Y., Cam Ha, D., Virelizier, H., Kondorosi, E., and Kondorosi, A. 1992. Rhizobium meliloti nod $\mathrm{M}$ and $\operatorname{nod} \mathrm{N}$ genes are common $\operatorname{nod}$ genes: $\operatorname{nod} \mathrm{M}$ encodes functions for efficiency of Nod signal production and bacteroid maturation. J. Bacteriol. 174:7555-7565.

Becker, A., Schmidt, M., Jäger, W., and Pühler, A. 1995. New gentamicin-resistance and lacZ promoter-probe cassettes suitable for insertion mutagenesis and generation of transcriptional fusions. Gene 162:3739.

Beringer, J. E., Brewin, N. J., and Johnston, W. B. 1980. The genetic analysis of Rhizobium in relation to symbiotic nitrogen fixation. Heredity 45:161-186.

Breedveld, M. W., and Miller, K. J. 1994. Cyclic $\beta$-glucans of members 
of the family Rhizobiaceae. Microbiol. Rev. 58:145-161.

Dénarié, J., and Debellé, F. 1996. Rhizobium lipo-chitooligosaccharide nodulation factors: Signaling molecules mediating recognition and morphogenesis. Annu. Rev. Biochem. 65:503-35.

Dénarié, J., Debellé, F., and Rosenberg, C. 1992. Signaling and host range variation in nodulation. Annu. Rev. Microbiol. 46:497-531.

Ditta, G., Stanfield, S., Corbin, D., and Helinski, D. R. 1980. Broad host range DNA cloning system for Gram negative bacteria: Construction of a gene bank of Rhizobium meliloti. Proc. Natl. Acad. Sci. USA 77:7347-7351.

Gage, D. J., Bobo, T., and Long, S. 1996. Use of green fluorescent protein to visualize the early events of symbiosis between Rhizobium meliloti and alfalfa. J. Bacteriol. 178:7159-7166.

Györgipal, Z., Iyer, N., and Kondorosi, A. 1988. Three regulatory nodD alleles of diverged flavonoid-specificity are involved in host-dependent nodulation by Rhizobium meliloti. Mol. Gen. Genet. 212:85-92

Hentze, M. W. 1994. Enzymes as RNA binding proteins: A role for (di)nucleotide-binding domains? Trends Biochem. Sci. 19:101-103.

Hirsch, A. M. 1992. Developmental biology of legume nodulation. New Phytol. 122:211-237.

Hirsch, A. M., Long, S. R., Bang, M., Haskings, N., and Ausubel, F. M. 1982. Structural studies of alfalfa roots infected with nodulation mutants of Rhizobium meliloti. J. Bacteriol. 151:411-419.

Jensen, H. L. 1942. Nitrogen fixation in leguminous plants. I. General characters of root nodule bacteria isolated from species of Medicago and Trifolium in Australia. Proc. Linn. Soc. NSW 66:98-108.

Jiménez-Zurdo, J. I., Frugier, F., Crespi, M. D., and Kondorosi, A. 2000. Expression profiles of 22 novel molecular markers for organogenetic pathways acting in alfalfa nodule development. Mol. Plant-Microbe Interact. 13:96-106.

Kannenberg, E. L., and Brewin, N. J. 1994. Host-plant invasion by Rhizobium: The role of cell-surface components. Trends Microbiol 2:277-283

Kapp, D., Niehaus, K., Quandt, J., Müller, P., and Pühler, A. 1990. Cooperative action of Rhizobium meliloti nodulation and infection mutants during the process of forming mixed infected alfalfa nodules. Plant Cell. 2:139-151.

Kerppola, T. K., and Kahn, M. L. 1988. Symbiotic phenotypes of auxotrophic mutants of Rhizobium meliloti 104A14. J. Gen. Microbiol. 134:913-919

Kiss, G. B., Vincze, É., Kálman, Z., Forrai, T., Kondorosi, A. 1979. Genetic and biochemical analysis of mutants affected in nitrate reduction in Rhizobium meliloti. J. Gen. Microbiol. 113:105-118.

Kondorosi, E., Gyuris, J., Schmidt, J., John, M., Duda, E., Hoffmann, B., Schell, J., and Kondorosi, A. 1989. Positive and negative control of nod gene expression in Rhizobium meliloti is required for optimal nodulation. EMBO J. 8:1331-1340.

Kondorosi, E., Buiré, M., Cren, M., Iyer, N., Hoffamnn, B., and Kondorosi A. 1991. Involvement of the $\operatorname{syrM}$ and $\operatorname{nod} \mathrm{D} 3$ genes of Rhizobium meliloti in nod gene activation and in optimal nodulation of the plant host. Mol. Microbiol. 5:3035-3048.

Kowalski, M. 1970. Transducing phages of Rhizobium meliloti. Acta Microbiol. Pol. Ser. A Microbiol. Gen. 19:104-114.

Leigh, J. A., Signer, E. R., and Walker, G. C. 1985. Exopolisaccharidedeficient mutants of Rhizobium meliloti that form ineffective nodules. Proc. Natl. Acad. Sci. USA. 82:6231-6235.

Meade, H. M., Long, G. B., Ruvkun, G. B., Brown, S. E., and Ausubel,
F. M. 1982. Physical and genetic characterization of symbiotic and auxotrophic mutants of Rhizobium meliloti induced by transposon Tn5 mutagenesis. J. Bacteriol. 149:114-122.

Miller, J. H. 1972. Page 352 in: Experiments in Molecular Genetics. Cold Spring Harbor Laboratory Press, Cold Spring Harbor, NY, U.S.A.

Müller, P., Hynes, M., Kapp, D,. Niehaus, K., and Pühler, A. 1988. Two classes of Rhizobium meliloti infection mutants differ in exopolysaccharide production and in coinoculation properties with nodulation mutants. Mol. Gen. Genet. 211:17-26.

Mulligan, J., and Long, S. 1985. Induction of Rhizobium meliloti nodC expression by plant exudate requires nodD. Proc. Natl. Acad. Sci. USA 82:6609-6613.

Ninner, B. M., and Hirsch, A. M. 1998. How many Rhizobium genes, in addition to nod, nifffix, and exo, are needed for nodule development and function? Symbiosis 24:51-102.

Pain, A. N. 1979. Symbiotic properties of antibiotic-resistant and auxotrophic mutants of Rhizobium leguminosarum. J. Appl. Bacteriol. 47:53-64

Roche, P., Debellé, F., Maillet, F., Lerouge, P., Faucher, C., Truchet, G., Dénarié, J., and Promé, J.-C. 1991. Molecular basis of symbiotic host specificity in Rhizobium meliloti: nod $\mathrm{H}$ and nodPQ genes encode the sulfation of lipo-oligosaccharide signals. Cell 67:1131-1143.

Rossbach, S., Rasul, G., Schneider, M., Eardly, B., and de Bruijn, F. J. 1995. Structural and functional conservation of the rhizopine catabolism (moc) locus is limited to selected Rhizobium meliloti strains and unrelated to their geographical origin. Mol. Plant-Microbe Interact. 8:549-559.

Schultze, M., and Kondorosi, A. 1992. Regulation of symbiotic root development. Annu. Rev. Genet. 32:33-57.

Simon, R. 1984. High frequency mobilization of gram-negative bacterial replicons by the in vitro constructed Tn5-Mob transposons. Mol. Gen. Genet. 196:413-420.

Spaink, H. P. 1995. The molecular basis of infection and nodulation by rhizobia: The ins and outs of sympathogenesis. Annu. Rev. Phytopathol. 33:345-368

Taté, R., Riccio, A., Caputo, E., Iaccarino, M., and Patriarca, E. J. 1999. The Rhizobium etli met $\mathrm{Z}$ gene is essential for methionine biosynthesis and nodulation of Phaseolus vulgaris. Mol. Plant-Microbe Interact. $12: 24-34$

Truchet, G., Barker, D. G., Camut, S., de Billy, F., Vasse, J., and Huguet, T. 1989. Alfalfa nodulation in the absence of Rhizobium. Mol. Gen. Genet. 219:65-68

Vasse, J., DeBilly, F., Camut, S., and Truchet, G. 1990. Correlation between ultraestructural differentiation of bacteroids and nitrogen fixation in alfalfa nodules. J. Bacteriol. 172:4295-4306.

Wexler, M., Gordon, D. M., and Murphy, P. J. 1996. Genetic relationships among rhizopine-producing Rhizobium strains. Microbiology 142:1059-1066.

Williams, M. N. W., Hollinsworth, R. I., Klein, S., and Signer, E. R. 1990. The symbiotic defect of Rhizobium meliloti exopolysaccharide mutants is suppressed by lps $Z+$, a gene involved in lipopolysaccharide biosynthesis. J. Bacteriol. 172:2622-2632.

Zelenaya-Troitskaya, O., Perlman, P. S., and Butow, R. A. 1995. An enzyme in yeast mitochondria that catalyzes a step in branched-chain amino acid biosynthesis also functions in mitochondrial DNA stability. EMBO J.14:3268-3276. 